\title{
DIRETRIZES PARA GESTÃO PARTICIPATIVA DAS ÁGUAS SUBTERRÂNEAS
}

\section{Carlos Magno de Souza Barbosa}

Engenheiro civil. Mestrando em Engenharia Sanitária e Ambiental - UFRN. Bolsista CNPq - CT-HIDRO. E-mail: carlosmagno25@hotmail.com

Recebido em maio de 2006 e aceito em outubro de 2006

\section{RESUMO}

Os recursos hídricos subterrâneos desempenham um papel importante, quando não fundamental, para o suprimento de água potável às populações. Para obter o uso racional deste recurso se faz necessária uma gestão eficiente que atenda as necessidades dos usuários de forma sustentável. A gestão participativa através da implantação dos comitês de bacias vem se mostrando uma ferramenta fundamental para alcançar os objetivos comuns. Este trabalho tem como finalidade apresentar os princípios da gestão participativa e as bases para operação dos comitês dos usuários da bacia.

Palavras-chave: Gestão participativa; águas subterrâneas; recursos hídricos.

\section{PRINCIPLES OF THE PARTICIPATIVE MANAGEMENT OF GROUNDWATER}

\begin{abstract}
The groundwater is an important resource for the supplement of drinking water to the populations. For the rational use of this resource it is necessary an efficient management that takes care of the necessities of the users with sustainable form. The participative management through the implantation of the committees of basins is a basic tool to reach the common objectives. This work has the purpose to present the principles of the participative management and the bases for operation of the committees of the users of the basin.
\end{abstract}

Key-words: Participative management; groundwater; water resources. 


\section{DIRETRIZES PARA GESTÃO PARTICIPATIVA DAS ÁGUAS SUBTERRÂNEAS}

\section{INTRODUÇÃO}

Tradicionalmente, a gestão das águas subterrâneas e o planejamento hidrológico têm sido realizados a partir de gestores estaduais, centralizados e burocratizados. Gradualmente, está sendo implantado um processo de descentralização, onde não havia a participação dos usuários na tomada de decisões, mas aos poucos essa realidade vem sendo mudada através da implantação de comitês de bacias.

No momento, a discussão da relação sociedade-recursos naturais diante de uma aparente crise, faz questionar sobre a eficiência da atual e futura da gestão tradicional vigente no uso do recurso. Neste sentido, a Assembléia Geral da Rede Internacional de Organismos de Bacias, expõe em um documento (RIOC, 1998) que a experiência adquirida em gestão das águas pôs em evidência a necessidade para associar, de maneira institucional, a sociedade civil, em mecanismos de gestão descentralizada dos recursos hídricos, com o propósito de buscar uma satisfação ótima e adaptada às necessidades diversificadas e em constante crescimento.

Os mananciais hídricos subterrâneos são tradicionalmente utilizados como fontes de abastecimento d'água para uso doméstico, industrial ou agrícola. A qualidade de suas águas, aliada à facilidade de extração em locais com escassez de águas de superfície, tem sido um fator importante e decisivo para o desenvolvimento de sistemas de extração em larga escala e de reduzidos custos visando satisfazer, quase sempre, demandas cada vez mais elevadas. Serviços públicos ineficientes ou muitas vezes inexistentes podem também contribuir para a busca de soluções mais imediatas e sem o devido controle por parte da comunidade.

A gestão da água subterrânea, segundo Nobre \& Nobre (2000), especialmente nas áreas metropolitanas, onde o crescimento populacional é cada vez maior e a necessidade da água para abastecimento em decorrência disto também é elevada ficou evidente, mostrando ser essencial para que se possa dar condições de realização de um gerenciamento integrado entre as águas superficiais e subterrâneas.

A partir da visão moderna da importância da água não só como essencial à vida, mas também como um bem dotado de valor econômico, as águas subterrâneas se destacam principalmente pelos conflitos já existentes, devido a escassez atual, com previsões piores no futuro. As soluções para os problemas requerem ações integradas, sensatas e participativas, com vistas ao aperfeiçoamento dos instrumentos que garantam a preservação dos recursos hídricos. As tendências mais modernas apontam para uma visão holística da água, isto é, um entendimento que considere não só as águas superficiais, mas também as subterrâneas.

A estratégia participativa na gestão tem virtudes e problemas. É interessante salientar duas virtudes: a partir das diferentes percepções, experiências e pontos de vista dos diferentes atores, pode-se chegar a um melhor diagnóstico, uma melhor interpretação da realidade. O resultado seguramente não será uma reconstrução objetiva da realidade, mas pelo menos será intersubjetiva tendendo a diminuir as subjetividades a partir da interação grupal. Também, este tipo de gestão promove o ambiente adequado para confrontar e negociar os diferentes interesses e objetivos dos participantes, permitindo a elaboração do 
consenso necessário para levar a diante o projeto; à medida que a interação vai avançando, as partes vão adquirindo um compromisso crescente com o avanço nos processamentos do projeto. O problema principal que afeta à gestão participativa pode estar nas diferenças de poder existentes entre os atores sociais participantes e que tendem a ser refletidos para o interior do comitê.

Primeiramente, convém denominar usuário só pelo fato de usar o recurso, no qual se divide em vários seguimentos da população: particulares, agricultores, industriais, empresários, etc. Nos documentos elaborados durante a Conferencia Internacional sobre a Água e Meio Ambiente em Dublin, se define muito bem a água numa perspectiva social, econômica e ambiental e se destaca a participação na gestão. Em todo o processo de planejamento e gestão implica numa ação transformadora da realidade, uma intervenção em um sistema que gerará uma situação inicial e uma situação final, e a multiplicidade de regras fazem da água um caso especial. O planejamento do uso da água e sua gestão devem ser sempre legitimados socialmente e guiados pela premissa de igualdade.

\section{GESTÃO INTEGRADA DE RECURSOS HÍDRICOS}

Solanes e Getches (1998) entendem que os princípios básicos da gestão integrada de recursos hídricos (GIRH) são:

- Eficiência econômica (reconhecimento do valor da água, redistribuição do recurso de acordo com mecanismos de mercado, atenção para as situações marginais, superar a noção de inelasticidade da demanda por baixos custos de produção com relação a o valor do seu uso);

- Justiça distributiva (as necessidades da sociedade mudaram, e as leis em vigência propiciam destinação do recurso ineficiente e injusto);

- Sustentabilidade ecológica (aspecto que não só envolve a provisão segura para o homem, mas também as necessidades florofaunísticas do ambiente);

- Equilíbrio na tomada de decisões (que supõe uma vocação de não setorial das instituições técnicas e administrativas envolvidas, com participação informada dos cidadãos, e que dirija os planejamentos adaptados aos ideais sociais e possibilidades econômicas de cada região).

A diferença da concepção historicamente aceita da gestão da água, dedicada quase exclusivamente ao desenvolvimento dos recursos hídricos orientada para o abastecimento, vem sendo transformada numa visão mais evoluída e racional da gestão orientada para a demanda. Não significa só manipular o recurso físico, mas também influenciar o modo que os usuários convivem com este recurso escasso (USUNOFF, et al; 2000).

Todos os recursos, por sua natureza, são escassos com relação a sua demanda (IDB, 1999). Lord e Israel (1996) propõem a existência de um contínuo, que vai desde um extremo onde estão os objetivos mais abstratos e gerais (sustentabilidade, diminuição da pobreza, proteção ambiental), até o extremo oposto onde se localizam os objetivos específicos e de maiores detalhes (construção de represas, zoneamento de planícies 
inundáveis, provisão de água potável). Entre esses extremos estão os problemas vinculados ao uso da água:

a) externalidades (positivas ou negativas) que se manifestam quando as ações de um setor afetam o bem-estar de outro setor, e que configuram situações de assimetria;

b) acesso aberto, quer dizer que o uso do recurso é aberto a todos os setores, embora o maior ou menor uso defina as quantidades que cada setor pode usar, e que dirige a uma situação simétrica porque cada usuário produz um custo que é distribuído entre todos os usuários;

c) interesse públicos, que se produzem quando um bem (a água, neste caso) deve ser distribuído a todos em quantidades iguais e tal ação não supõe um lucro direto, pois está por conta dos governos; e

d) escassez que é gerada quando um bem é requerido em quantidades maiores que as disponíveis para um determinado custo.

Para as bases conceituais, Lord e Israel (1996) reconhecem a existência de três elementos: os atores (indivíduos ou os grupos de usuários), a ambiente (onde se encontra o recurso) e as instituições (o corpo de leis e normas que regulam o uso).

- Atores: definem a demanda, e no caso da água os modelos de comportamento sugerem que o custo da água regule seu uso (a visão dos economistas, que é certamente discutível).

- Ambiente: não só inclui a ambiente natural, mas também a posição e ações do homem neste ambiente (infra-estrutura antrópica).

- Instituições: são as regras que concedem direitos ou impõem deveres aos atores.

Tais regras devem levar em conta:

a) Alcance: o conjunto de efeitos sobre os sistemas humanos e ambientais que uma determinada política, programa ou projeto afeta no presente e no futuro. Os efeitos podem ser primários ou diretos (uso consultivo, uso da água superficial, e qualidade da água) e secundários ou indiretos (quantidade e distribuição dos benefícios, saúde, qualidade de vida, etc.).

b) Participação: é essencial que todos os grupos de usuários estejam representados nas decisões de uso dos recursos hídricos. A forma mais descentralizada de participação é são os comitês de bacias hidrográficas.

c) Poderes: as organizações responsáveis pela GIRH devem possuir poder, idoneidade e competência para o desenvolvimento do recurso, sua distribuição, e o controle de sua qualidade. Isto não supõe uma visão estadista, porque está claro que não há razões para se opor à tendência atual de privatização dos serviços. Deve-se salientar que os gestores institucionais devem priorizar a administração dos direitos de propriedade sobre a água, o regulamento da atividade privada em relação aos custos externos, e muito fundamentalmente a preservação da qualidade do recurso. 
d) Informação: a geração e compilação de informações podem se tornar um poço sem fundo no qual são depositadas quantidades consideráveis de dinheiro sem que renda benefícios. A tendência atual é que as organizações a cargo da informação devem assumir essa responsabilidade levando em conta que há ocasiões em que a incerteza é preferível (economicamente) a promover relatórios de abaixo benefício.

e) Tomada de decisões: quando se trata de tomar decisões sobre políticas públicas ou programas, há três formas: negociação (os bens e serviços se estabelecem através de discussões, como dos mercados de água), comando (as decisões são tomadas por uma escala hierárquica e as transmite as instancias inferiores), e representação (entidades de ordem menor têm peso relevantes decisões de âmbitos superiores, igual ao Senado em um sistema democrático). Qualquer sistema de gestão dos recursos hídricos deve incorporar o melhor destas formas de tomada de decisões.

f) Benefícios e custos: aqui se incluem todas as conseqüências materiais, até mesmo as de ordem monetárias. É necessário analisar: a magnitude dos custos e benefícios (analisando somente projetos eficientes e viáveis); a incidência dos custos e benefícios (respondendo a princípios de igualdade e justiça, no qual às vezes pode ser medido pela "disposição para pagar”, com atenção para a situação das classes mais pobres); e a influência no comportamento de tais custos e benefícios (se um projeto for bem planejado serão criados incentivos para que os grupos ou indivíduos interessados respondam aos objetivos da gestão dos recursos hídricos). É importante para evitar os subsídios sem causa justificada, porque invariavelmente conduzem a sobreutilização da água.

\section{BASES PARA A OPERAÇÃO DO COMITÊ DE USUÁRIOS}

A estruturação de um Comitê de Usuários deve-se apoiar em ações internas, para seus membros, e externas, para a comunidade e instituições que as representam. Ambos são de importância vital para atingir o mínimo de sucesso na gestão do comitê.

\section{Linhas de ação interna}

Neste aspecto se ressaltam três premissas que contribuem para consolidar a eficácia e eficiência do comitê:

1) Cadastramento de usuários: embora que possa parecer óbvio, cada um dos sócios deve saber exatamente quem o representa, conhecer propriamente os interesses dos seus representados, e os dos outros membros. Deve saber sobre a informação, tecnologia e vínculos institucionais disponíveis, etc. Em resumo, o porquê e para que da própria participação e dos outros membros no comitê. Deve ser lembrada, também, a legitimação da representatividade desses membros no comitê que representem associações de usuários e garantia de que a representação do usuário particular seja ou não abastecida do sistema de água atual.

2) Capacitação e sensibilização dos membros: Primeiramente, obter conhecimentos básicos sobre a dinâmica do recurso e a caracterização do local em condições apropriadas para a comunidade em geral, não especializada. Isto é especialmente importante no caso de usuários de comitê de água subterrânea, pois é um recurso hídrico cujas particularidades são, em geral, pouco conhecidas. A sensibilização se refere a que os membros reconheçam 
como princípio guia do comitê o caráter social, o valor econômico e as limitações e vulnerabilidade do recurso.

3) Coordenação interinstitucional de programas e projetos: As ligações ou conexões que existem entre instituições que agem como facilitadores da comunicação são de três tipos:

a - Coordenação: quando duas ou mais instituições coordenam suas atividades para duplicar esforços mas cada uma continua operando em forma autônoma.

b - Cooperação: implica algo mais que uma operação paralela já que cada um deve dar algo de sua autonomia se quer receber algum benefício. Constitui em uma troca recíproca de informação e tecnologia entre instituições e indivíduos com interesses mútuos.

c - Colaboração: é um processo mais intensivo e de maior interação. Todas as instituições interagem com uma meta comum, por meio de próprios recursos.

As principais limitações na colaboração são:

- Jurisdições confusas dentro de um sistema regional ou de bacias;

- Confusão no nível de competência e/ou vantagens comparativas de cada instituição. Surgem conflitos quando uma mesma atividade é de competência de mais de uma instituição;

- Influências de poder e diversos interesses criados entre técnicos e dirigentes do setor público.

\section{Linhas de ação externa}

É essencial levar adiante uma política de promoção da gestão do comitê centrada em dois aspectos:

1) Como base de informação e motivação social: Toda gestão institucional que promova estabelecer as bases no âmbito social, primeiramente requer que se conheçam as ações de gestão do comitê, e em segundo lugar que transmita motivação e confiança para a sociedade. A sociedade deve considerar o comitê como garantia de sua qualidade de vida, ao menos no que se refere ao uso da água.

2) Como base da coordenação interinstitucional: A política de promoção de um programa de gestão de águas subterrâneas deve considerar as informações periódicas sobre cada fase de desenvolvimento, transformando o programa de atividades em informações que correlacionem os atores, entidades, grupos, unidades administrativas ou técnicas e organizacionais, responsável para a execução dessas atividades.

Deve contar também com um bom mecanismo de fiscalização para identificar problemas e assegurar a comunicação entre os organismos envolvidos e os responsáveis de outras áreas da gestão, onde cada um contribui com a sua especificidade sem perder o próprio objetivo como instituição. Isto é especialmente importante ao integrar o processo de gestão da água ao de outros recursos e ao planejamento de usos do solo. 


\section{A GESTÃO DAS ÁGUAS SUBTERRÂNEAS}

A gestão das águas subterrâneas dentro do contexto da GIRH significa equilibrar a exploração do recurso (em termos de quantidade, qualidade e relações relevantes com outros recursos naturais) com o incremento da demanda de água utilizada para o desenvolvimento econômico e para a subsistência. O equilíbrio terá que considerar a eficiência, a justiça e a sustentabilidade a longo prazo com o propósito de manter tanto a qualidade como a quantidade aos níveis desejados. Porém, na prática, as águas subterrâneas são geralmente geridas separadamente:

- As águas superficiais, até mesmo quando estas fazem parte do ciclo de hidrológico total, como muito em quantidade como em qualidade;

- Os esgotos das cidades, até mesmo quando estas representam simultaneamente um recurso adicional e uma ameaça potencial de contaminação para as águas subterrâneas;

- O manejo do solo, até mesmo quando os aqüíferos estejam ameaçados pela contaminação causada pela urbanização, o desenvolvimento industrial, a atividade agrícola e as empresas de mineração.

Um plano de gestão de águas subterrâneas deve, então, fazer parte de um plano da GIRH com o propósito de evitar as situações acima mencionadas. Então, o plano de gestão das águas subterrâneas, como o plano nacional, identificará as ações necessárias para contribuir efetivamente para a gestão dos recursos hídricos. Este plano fará uso da participação dos usuários e da criação de capacidades, estabelecerá as necessidades dentro do marco social e econômico mais amplo e reconhecerá claramente as situações hidrogeológicas, socioeconômicas e institucionais.

A delimitação apropriada das fronteiras para estabelecer a área do planejamento e gestão do recurso de águas subterrâneas é um tema difícil que geralmente transcende os limites políticos e administrativos. Também, em algumas situações socioeconômicas e políticas do mundo real, as decisões para a gestão do risco — dirigidas a abordar a extração excessiva e/ou a contaminação severa da águas subterrâneas - anularão enfoques da gestão integrada. Outros obstáculos para um enfoque integrado são a falta de capacidade institucional, a disponibilidade limitada de fundos ou, simplesmente, as políticas.

As estratégias de um plano de gestão das águas subterrâneas devem ser apropriadas para a situação específica:

- Situação inicial onde existe uma extração insignificante de águas subterrâneas, unicamente se precisarão registrar os poços e mananciais e traçar mapas do recurso;

- Em situação de tensão incipiente com poucas demandas e conflitos locais irreconciliáveis é adequado utilizar ferramentas simples de gestão para uma boa distribuição que conte com o apoio de um marco regulativo;

- Em situação de tensão significativa na qual a extração afeta o regime natural e os usuários será necessário empregar uma política de desenvolvimento das águas subterrâneas e um marco regulativo baseado na valoração de recursos; 
- Situação insustentável, onde exista uma extração incontrolada e excessiva e uma deterioração irreversível do aqüífero, existe a necessidade urgente de políticas, legislação e regulamentação muito mais rigorosa, e de mecanismos de gestão mais severos.

\section{PARTICIPAÇÃO DA SOCIEDADE NA GESTÃO DA ÁGUA}

A sociedade brasileira vem se mobilizando para participar da gestão das águas desde o início das discussões em torno da elaboração do aparato legal da área de recursos hídricos.

Essa mobilização acontece tanto por meio de organizações civis não governamentais de âmbito nacional, quanto por ações pontuais que ocorrem no meio escolar e municipal visando à conservação e preservação da água. É crescente o numero de atividades esparsas no país visando à conscientização da sociedade a respeito dos problemas ambientais e, principalmente, da necessidade de água de boa qualidade.

Os comitês de bacia hidrográfica são como "células" do Sistema Nacional de Gerenciamento de Recursos Hídricos onde a presença da sociedade é expressiva. Além dos comitês, dependendo do processo de implementação do Sistema, a participação da sociedade civil acontece de outras maneiras associações, onde participam usuários da água e organizações não governamentais. Houve também aumento substancial no número de consórcios intermunicipais de bacias nos últimos anos.

Outro indicador da participação da sociedade no debate dos temas relacionados aos recursos hídricos é o aumento da quantidade de cursos de nível universitário e de pósgraduação dedicados à área. Ainda, os cursos de gestão de recursos hídricos de curta duração, realizados em todo o território nacional, tiveram sempre uma demanda muito superior ao número de vagas ofertadas, sendo oferecidos não só pelos órgãos gestores de recursos hídricos como também por diversas outras instituições, inclusive privadas, evidenciando o interesse da sociedade pelo tema.

\section{CONCLUSÕES}

O processo de planejamento e gestão das águas subterrâneas, tradicionalmente realizado pelos órgãos gestores estaduais, centralizados e burocratizados, está gradualmente sendo descentralizado e abrindo oportunidades para a participação dos usuários na tomada de decisões, através da implantação de comitês de bacias.

A gestão participativa das águas subterrâneas através dos comitês de bacias promove o ambiente adequado para confrontar e negociar os diferentes interesses e objetivos dos participantes, permitindo a elaboração do consenso necessário para levar a diante o projeto.

A partir da visão moderna da importância da água não só como essencial à vida, mas também como um bem dotado de valor econômico, as águas subterrâneas atingem uma dimensão, principalmente frente aos conflitos já existentes, devido à escassez atual, com previsões piores no futuro. As soluções para os problemas requerem ações integradas, sensatas e participativas, com vistas ao aperfeiçoamento dos instrumentos que garantam a 
preservação dos recursos hídricos. As tendências mais modernas apontam para uma visão holística da água, isto é, um entendimento que considere não só as águas superficiais, mas também as subterrâneas.

É importante que os Estados criem meios administrativos e legais que permitam o gerenciamento sustentável das águas subterrâneas, compatíveis devidamente com a gestão integrada de recursos hídricos, em consonância com a Lei Federal 9.433/97.

Deve-se evitar a deturpação das normas gerais e garantir, através de fiscalização, que as leis definidas no papel, estejam de fato sendo cumpridas para todos. Porém, se não houver uma regulamentação sólida e uma estrutura institucional organizada, de nada adiantarão tais medidas.

A participação da sociedade é imprescindível para que normas e diretrizes de conservação dos recursos hídricos sejam aceitas e obedecidas. Para tal, ela necessita ser corretamente informada sobre a questão ambiental.

As águas subterrâneas, mais do que uma reserva de água, devem ser consideradas como um meio de acelerar o desenvolvimento econômico e social de regiões extremamente carentes no Brasil. É importante, para o semi-árido do nordeste, a abordagem de gerenciamento integrado dos recursos hídricos, como meio de se criar uma infra-estrutura básica que permita à população ultrapassar, sem muito sacrifício, os períodos de estiagem. Nesse particular, pela sua disponibilidade e facilidade de exploração, as águas subterrâneas podem exercer um papel vital.

\section{AGRADECIMENTOS}

O presente trabalho foi realizado com apoio do CNPq, Conselho Nacional de Desenvolvimento Científico e Tecnológico - Brasil.

\section{REFERÊNCIAS BIBLIOGRÁFICAS}

HERRÁIZ, A. S. La contaminación de las aguas subterráneas: una responsabilidad mora, política y ambiental. II Congresso Ibérico sobre planeamento e gestão de água. Porto, Portugal. 2000.

HIRATA, R. Gestão da Qualidade dos Recursos Hídricos. In: Simpósio Nacional sobre o Uso da Água na Agricultura, Passo Fundo/RS. 2004.

LORD, W. e ISRAEL, M. A proposed strategy to encourage and facilitate improved water resource management in Latin America and the Caribbean. Environment Division, Social Programs and Sustainable Development Department, InterAmerican Development Bank, Washington, D.C., 119 p. 1996.

MASSONE, H, CIONCHI, J. BOCANEGRA E., LIZARDO C. Gestión de acuíferos y participación comunitaria. El comité de usuarios como herramienta de gestión. 
UNESCO. Programa Hidrológico Nacional para América Latina y el Caribe Centro de Geologia de Costas y Cuaternario- UNMdP. 2000.

NOBRE, M. de M. M., e NOBRE, R. C. M. Uso sustentável de águas subterrâneas na região metropolitana de Maceió. I Congresso Mundial Integrado de Águas Subterrâneas. Fortaleza/CE. 2000.

R.I.O.C. - Red Internacional de Organismos de Cuenca. La participación de los usuarios en la gestión sostenible de los recursos hídricos. Asamblea General de la Red Internacional de Organismos de Cuenca. Salvador/BA, Brasil. 1998.

SAHUQUILLO, A. La calidad y la contaminación de las aguas subterráneas en España ¿ ¿Quo vadimus? Jornadas sobre la contaminación de las aguas. 1998.

SOLANES, M. \& GETCHES, D. Prácticas recomendables para la elaboración de leyes y regulaciones relacionadas con el recurso hídrico. Informe de Buenas Prácticas, Banco Interamericano de Desarrollo, Washington, D.C., Informe ENV-127, 103 p. 1998.

U.S.ENVIRONMENTAL PROTECTION AGENCY Drinking water regulations and health advisories.Offices of water. 1995. Disponível em: < URL http://www.epa.gov. > Acesso em: jun. 2005.

USUNOFF, E; PELUSO, F; CASTELAIN, J. G. \& MIRANDA, M. Hacia la gestión integrada de los recursos hídricos en la provincia de Buenos Aires, Argentina. I Congresso Mundial Integrado de Águas Subterrâneas. Fortaleza/CE. 2000. 